\title{
Thermal Stability of Nanocrystalline Gradient Inconel 718 Alloy
}

\author{
Jie Ding ${ }^{1, *}$, Yifan Zhang ${ }^{1}$, Tongjun Niu ${ }^{1}$, Zhongxia Shang ${ }^{1}$, Sichuang Xue ${ }^{1}$, Bo Yang ${ }^{1}$, Jin Li ${ }^{1}$, Haiyan Wang ${ }^{1,2} \mathbb{D}$ \\ and Xinghang Zhang ${ }^{1, *}$
}

1 School of Materials Engineering, Purdue University, West Lafayette, IN 47907, USA; zhan2592@purdue.edu (Y.Z.); niu35@purdue.edu (T.N.); shang19@purdue.edu (Z.S.); xue97@purdue.edu (S.X.); yang837@purdue.edu (B.Y.); vincentlijin@gmail.com (J.L.); hwang00@purdue.edu (H.W.)

2 School of Electrical and Computer Engineering, Purdue University, West Lafayette, IN 47907, USA

* Correspondence: ding173@purdue.edu (J.D.); xzhang98@purdue.edu (X.Z.)

check for updates

Citation: Ding, J.; Zhang, Y.; Niu, T.; Shang, Z.; Xue, S.; Yang, B.; Li, J.; Wang, H.; Zhang, X. Thermal Stability of Nanocrystalline Gradient Inconel 718 Alloy. Crystals 2021, 11, 53. https://doi.org/10.3390/cryst11010053

Received: 12 December 2020 Accepted: 2 January 2021 Published: 11 January 2021

Publisher's Note: MDPI stays neutral with regard to jurisdictional clai$\mathrm{ms}$ in published maps and institutional affiliations.

Copyright: $(\odot 2021$ by the authors. Licensee MDPI, Basel, Switzerland. This article is an open access article distributed under the terms and conditions of the Creative Commons Attribution (CC BY) license (https:// creativecommons.org/licenses/by/ $4.0 /)$.

\begin{abstract}
Gradient structures containing nanograins in the surface layer have been introduced into Inconel 718 (IN718) nickel-based alloy using the surface mechanical grinding treatment technique. The thermal stability of the gradient IN718 alloy was investigated. Annealing studies reveal that nanograins with a grain size smaller than $40 \mathrm{~nm}$ exhibited significantly better thermal stability than those with larger grain size. Transmission electron microscopy analyses reveal that the enhanced thermal stability was attributed to the formation of grain boundaries with low energy configurations. This study provides new insight on strategies to improve the thermal stability of nanocrystalline metals.
\end{abstract}

Keywords: nanocrystalline; thermal stability; IN718 alloy

\section{Introduction}

Nanograined (NG) metals containing a high volume fraction of grain boundaries have demonstrated much higher mechanical strength than their coarse-grained counterparts [1-3]. Severe plastic deformation (SPD) techniques such as equal channel angular pressing $[4,5]$ and high-pressure torsion [6-8], etc., have been proven effective in grain refinement of metallic materials. However, the same grain boundaries that contribute to the high strength also lead to deterioration of the thermal stability of NG metals [9-12]. The grain boundary energy of nanograins provides a large driving force for grain coarsening. For instance, grain boundary migration takes place at $300{ }^{\circ} \mathrm{C}$ for nanocrystalline $\mathrm{Nb}$ (obtained by high pressure torsion) with an average grain size of $75 \mathrm{~nm}$ [13]. Grain growth occurs at temperatures as low as $200{ }^{\circ} \mathrm{C}$ for nanocrystalline $\mathrm{Ni}$, accompanied by a substantial hardness drop [14]. In electrodeposited nanocrystalline $\mathrm{Ni}$ with an average grain size of 10-20 nm, grain coarsening occurs at $80{ }^{\circ} \mathrm{C}$ [15]. Similarly, grain growth takes place even at ambient temperature in nanocrystalline $\mathrm{Cu}$. The poor thermal stability hinders the application of NG metallic materials at elevated temperatures [16].

Recently, surface mechanical grinding treatment (SMGT) [17], surface mechanical attrition treatment (SMAT) [18-20] and surface mechanical rolling treatment (SMRT) [18] have been applied to introduce gradient microstructures into the surface of metallic materials to improve both strength and ductility. Gradient structures containing an NG top surface layer have been introduced into several types of metals [18,21-24]. It has been reported that these surface modification techniques are more effective than conventional SPD approaches in grain refinement [22]. In contrast to the poor thermal stability of nanograins in most prior studies, it was reported that nanograins smaller than the critical values $(70 \mathrm{~nm}$ for $\mathrm{Cu}$ and $43 \mathrm{~nm}$ for $\mathrm{Ni}$ ) were more stable than larger grains in gradient structured pure $\mathrm{Cu}$ and $\mathrm{Ni}$ fabricated using SMGT in liquid nitrogen [25]. The surprising observation of enhanced thermal stability of nanograins was attributed to the unique grain boundaries in 
low energy configurations generated during low-temperature SMGT $[25,26]$. This evidence implies that the thermal stability of NG alloys may not necessarily be deteriorated after grain refinement.

Inconel 718 (IN718) is a common precipitation-strengthened Ni-based superalloy used for application in high-pressure turbine discs in jet engines [27-35]. However, a majority of the published works focused on wrought IN718 alloys with coarse grains [36,37]. Studies on NG IN718 are limited. Besides, the high-temperature performance of IN718 is primarily determined by the high-density $\gamma^{\prime \prime}$ phases formed after annealing [36,38-45]. However, at temperatures above $650{ }^{\circ} \mathrm{C}$, the metastable $\gamma^{\prime \prime}$ phase transforms to stable $\delta$ phase over long-term exposure $[36,37,44,46]$. The application of IN718 alloy is therefore limited to temperatures below $650{ }^{\circ} \mathrm{C}$. In this study, gradient structures containing a severely deformed NG surface layer were introduced into IN718 alloy via the SMGT technique at liquid nitrogen temperature. Studies on the NG IN718 alloy at $700{ }^{\circ} \mathrm{C}$ for up to $100 \mathrm{~h}$ reveal that nanograins have outstanding thermal stability. The underlying nanograin stabilization mechanisms are discussed.

\section{Experimental}

\subsection{Materials and Processing}

The IN718 Ni-based alloy with a chemical composition as listed in Table 1 was subjected to SMGT. Prior to processing, a cylindric bar was solution-treated at $1100{ }^{\circ} \mathrm{C}$ for $1 \mathrm{~h}$ followed by water quenching (denoted as as-processed hereafter). During processing, the bar was rotated at a velocity of $400 \mathrm{rpm}$ while a WC/Co tool tip penetrated into the surface by $30 \mu \mathrm{m}$ and slid along the axial direction at a speed of $10 \mathrm{~mm} / \mathrm{min}$. The process was repeated 8 times to generate a substantial deformation zone. Liquid nitrogen was used as the coolant during processing. Subsequently, the processed samples were annealed in a vacuum furnace at $700{ }^{\circ} \mathrm{C}$ for 5,24 and $100 \mathrm{~h}$, followed by furnace cooling. Annealing was conducted when the vacuum reached $2 \times 10^{-6}$ torr.

Table 1. The chemical composition of IN718 alloy (in wt.\%).

\begin{tabular}{ccccccccc}
\hline $\mathbf{C r}$ & $\mathbf{F e}$ & $\mathbf{C o}$ & $\mathbf{N b}$ & $\mathbf{M o}$ & $\mathbf{A l}$ & $\mathbf{T i}$ & $\mathbf{T a}$ & $\mathbf{N i}$ \\
\hline 18.57 & 18.00 & 0.11 & 5.02 & 2.86 & 0.58 & 0.97 & $<0.01$ & Bal. \\
\hline
\end{tabular}

\subsection{Microstructure Characterizations}

The samples used for metallographic observations were ground and polished using the conventional metallographic preparation technique, and the observation was then carried out using an optical microscope. TEM samples were prepared using the focused ion beam (FIB) technique with an FEI Quanta 3D FEG Dual Beam FIB scanning electron microscope following typical protocols. The microstructure and chemical composition analyses of both the as-processed and annealed samples were performed on an FEI Talos 200X analytical transmission electron microscope operated at $200 \mathrm{kV}$, equipped with a Super-X energy-dispersive X-ray spectroscopy (EDS) detector. The grain orientation analyses were performed using the NanoMegas ASTAR (to generate an electron backscattering diffraction (EBSD)-like automated crystal orientation map with 4-nm spatial resolution) setup installed in the Talos 200X TEM microscope, and data analyses were conducted using OIM Analysis software.

\section{Results}

After SMGT, a severely deformed gradient structure formed on the surface, as shown in the optical microscopy image in Figure 1a. NG structures (as labeled by a dotted line) were observed on the topmost region of the gradient layer (based on TEM studies shown later). The Vickers hardness indents and the corresponding hardness along the depth direction were labeled, indicating the formation of gradient microstructures after SMGT. After annealing at $700{ }^{\circ} \mathrm{C}$, a sharp interface formed between the topmost NG region and the 
deeper region of the sample, as revealed by the optical microscopy images in Figure 1b,c. It is worth mentioning that the thickness of the NG region varies with positions due to the inhomogeneous penetration depth of the gradient structure after SMGT, with a maximum depth of $30 \mu \mathrm{m}$.

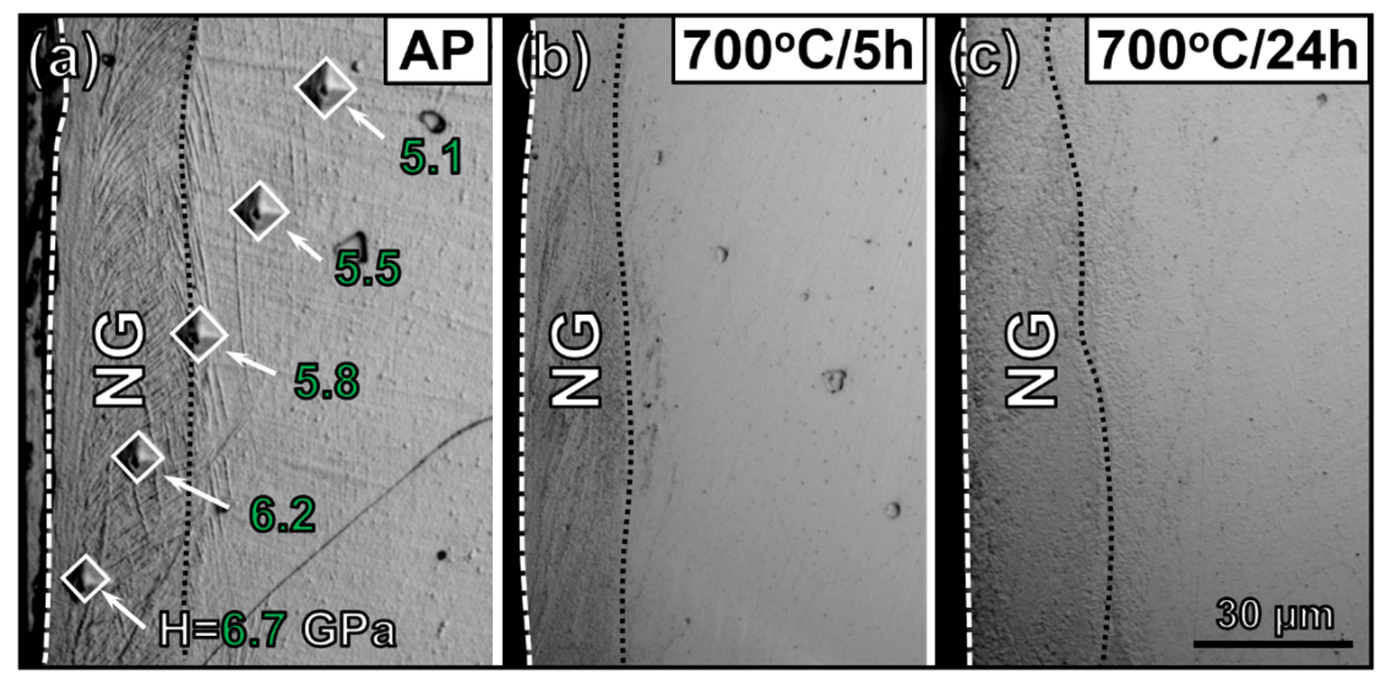

Figure 1. Optical microscopy images of (a) as-processed (AP) and annealed gradient IN718 alloy at $700{ }^{\circ} \mathrm{C}$ for (b) $5 \mathrm{~h}$ and (c) $24 \mathrm{~h}$. The topmost nanograined (NG) regions are labeled by dotted lines. Vickers indentation and corresponding hardness values (in GPa) are labeled.

The TEM image of the as-processed sample in Figure 2a reveals that NG structures formed near the surface of IN718 alloy after SMGT, as confirmed by the inserted selected area diffraction (SAD) pattern. It is worth mentioning that fine and coarse nanograin layers were observed in the NG region (referred to as FNG and CNG hereafter, respectively), as labeled by the dotted lines in Figure 2a. The TEM image in Figure 2b shows the alternately distributed FNG and CNG layers in the topmost NG region (at a depth range of 2-5 $\mu \mathrm{m}$ from surface). The corresponding grain size distribution profile reveals that the average grain size is 14 and $28 \mathrm{~nm}$ in the alternating FNG and CNG layers, respectively. The average grain size of the CNG layers increases gradually from $25 \mathrm{~nm}$ at a depth of $100 \mathrm{~nm}$ from the surface to over $32 \mathrm{~nm}$ at the depth of $2200 \mathrm{~nm}$ from the surface (as shown in Figure $2 b$ ), further confirming the formation of complex gradient microstructures. The corresponding scanning transmission electron microscopy (STEM) image and EDS maps of the NG region in Supplementary Figure S1 (see supplementary materials) reveal that the chemical composition remains uniform. The ASTAR inverse pole figure map in Figure $2 \mathrm{c}$ shows the nanograins with various orientations in both FNG and CNG layers. The grain boundary map in Figure $2 \mathrm{~d}$ shows that a majority of the grain boundaries in both the FNG and CNG layers are high-angle grain boundaries (HAGBs, indicated by blue lines). The fractions of low-angle grain boundaries (LAGBs) and coincidence site lattice (CSL) boundaries (indicated by red and yellow lines, respectively) are low. 

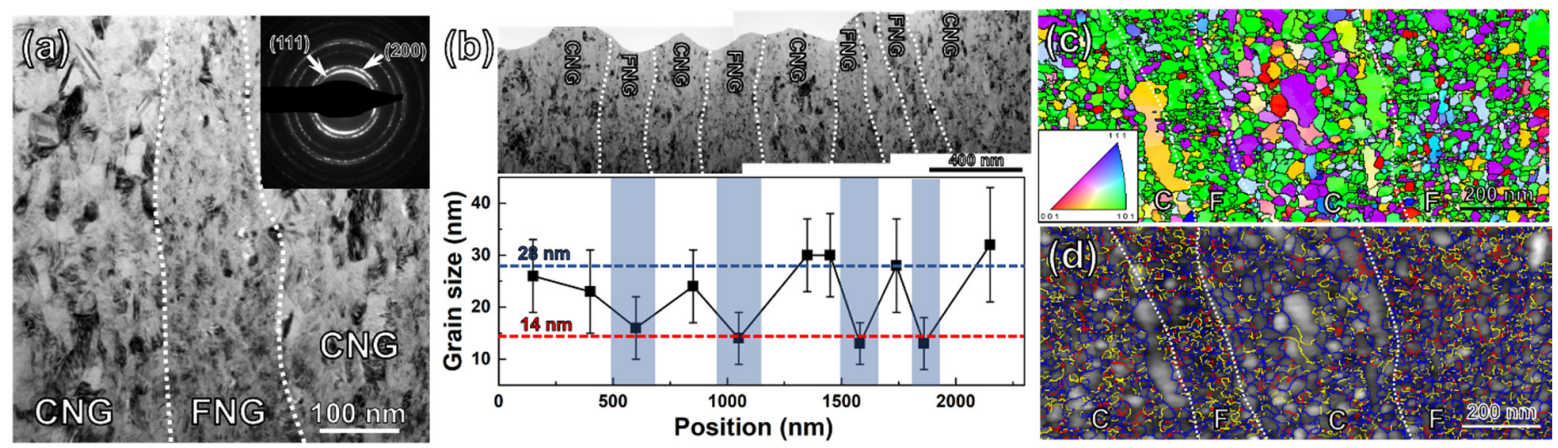

Figure 2. (a) TEM image showing the formation of an NG structure in the topmost region of the IN718 specimen after surface mechanical grinding treatment (SMGT). Fine nanograin (FNG) layers were sandwiched by coarse nanograin (CNG) layers. (b) TEM image of NG region and the corresponding grain size vs. position profile showing the grain size evolution of both FNG and CNG layers at various depth. The corresponding (c) ASTAR crystal orientation analyses and (d) grain boundary map showing the high-angle grain boundaries (blue lines), low-angle grain boundaries (red lines) and twin boundaries (yellow lines).

Upon annealing $\left(700^{\circ} \mathrm{C} / 24 \mathrm{~h}\right)$, the nanograins of the topmost $\mathrm{NG}$ region retained, whereas recrystallization and grain coarsening occurred in the rest of the gradient layers. Figure 3a shows the microstructure of the distinct interface (as denoted by a dashed line) formed between the thermally stable topmost NG area and the grain coarsened areas. Furthermore, the alternatively distributed FNG/CNG structures were sustained after annealing (as labeled by dotted lines in Figure 3a). The statistic distributions of grain size in Figure $3 \mathrm{~b}$ show that the average grain size of FNG and CNG layers in the thermally stable area is 18 and $37 \mathrm{~nm}$, respectively, whereas the grain size of the adjacent area coarsened to $90 \mathrm{~nm}$. The STEM images and corresponding EDS maps of both thermally stable and grain coarsened area in supplementary Figure S2a,b show that large Ni- and Nb-rich $\delta$ phases and $\mathrm{Al}-, \mathrm{Ni}$ - and $\mathrm{Nb}$-rich $\eta$ phases formed after annealing. The difference between these two areas is that nanoscale $\alpha$-Cr phases have higher density and smaller size in the thermally stable area than the grain coarsened area.
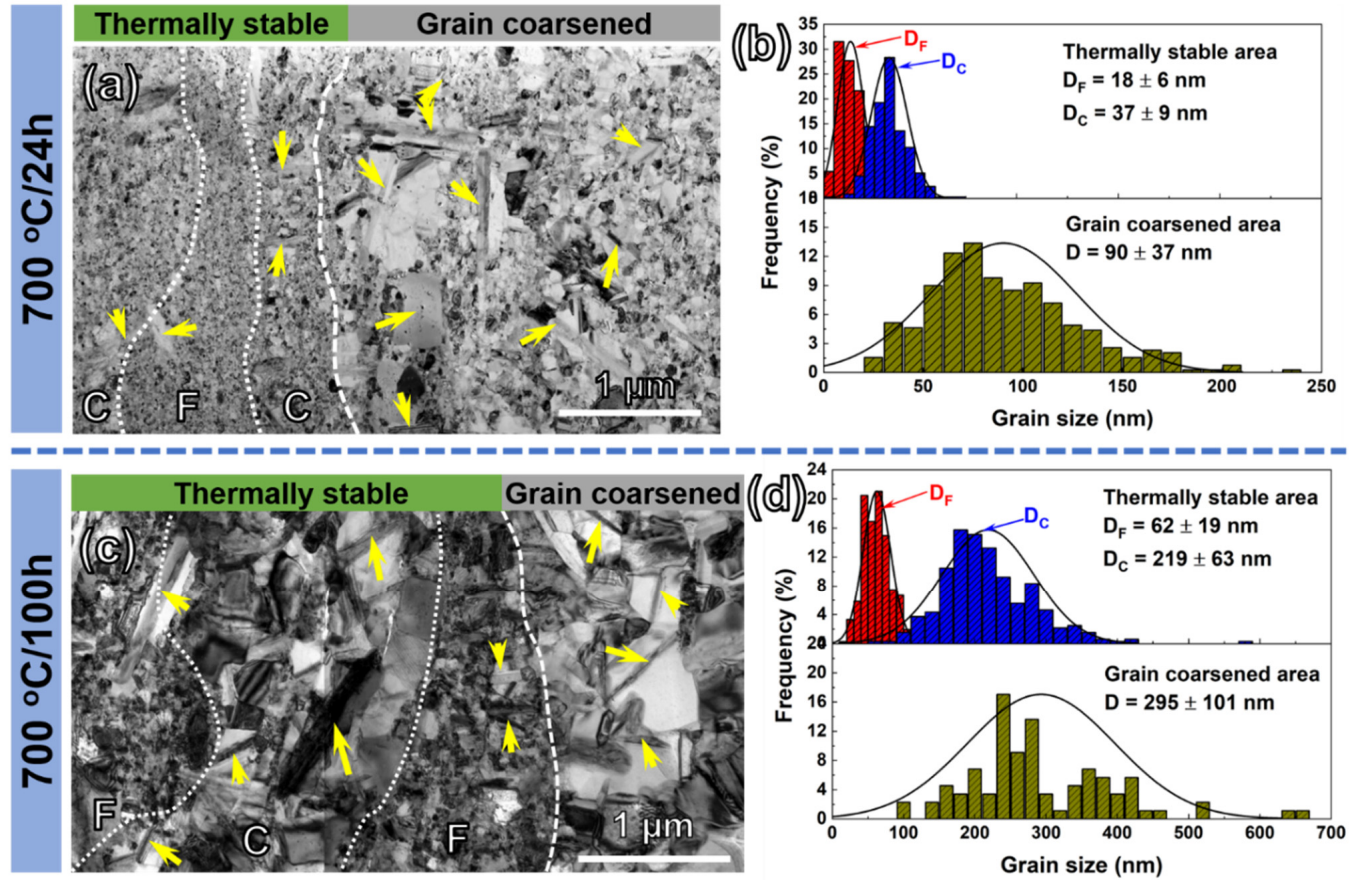

Figure 3. TEM images showing the sharp interface formed between the thermally stable area and the grain coarsened area of NG IN718 specimens after annealing at $700{ }^{\circ} \mathrm{C}$ for (a) $24 \mathrm{~h}$ and (c) $100 \mathrm{~h}$. (b,d) The corresponding statistic distributions revealing the average grain sizes of FNG $\left(D_{F}\right)$ and $C N G\left(D_{C}\right)$ layers in the thermally stable and grain coarsened area. 
Increasing the annealing time further to $100 \mathrm{~h}$ coarsened the grains in both thermally stable and grain coarsened areas of the NG region. However, the sharp interface between those two areas sustained, as labeled by the dashed line in Figure 3c. The alternatively distributed FNG/CNG structures were also observed, whereas the grain size difference between these two layers is much larger than the specimen annealed for $24 \mathrm{~h}$ (in Figure 3a). The statistical analyses reveal that the grain size of the FNG and CNG layers increased to 62 and $219 \mathrm{~nm}$, respectively (Figure 3d). In comparison, in the grain coarsened area, the grains coarsened further to $295 \mathrm{~nm}$.

\section{Discussion}

While grain boundaries in nanocrystalline metals improve mechanical strength, they provide a strong driving force for grain coarsening [9]. Grain coarsening of NG metals involves GB migration at a certain velocity $(v)$, which can be expressed as $[47,48]$ :

$$
v=M_{g b} \cdot \gamma_{g b} \cdot k
$$

where $M_{g b}$ represents the GB mobility, $\gamma_{g b}$ is the GB energy and $\kappa$ is the local grain boundary curvature. This equation implies that at least two approaches can be applied to alleviate grain coarsening: the kinetics-driven stabilization approach, in which grain coarsening is suppressed by pinning grain boundaries with second-phase Zener drag or by solute drag, and a thermodynamics approach, where lowering grain boundary energy can effectively reduce the driving force for grain coarsening [49-51]. Specifically, the driving force for grain coarsening of NG metals is the excess energy stored at the grain boundaries. Zhou et al. [25] reported that the grain boundary energy of NG Cu fabricated by SMGT declined from 0.52 to $0.25 \mathrm{~J} / \mathrm{m}^{2}$ when the average grain size decreased from 125 to $50 \mathrm{~nm}$ and showed a thermally stable NG layer when the average grain size is smaller than $70 \mathrm{~nm}$. The grain boundary energy reduction was partially attributed to the formation of low-energy grain boundaries, consisting of nanotwins and stacking faults (SFs), and partially ascribed to the grain boundary relaxation [25].

In this study, a gradient NG surface layer was introduced into IN718 alloy by SMGT. The topmost area of the NG region with smaller grain size exhibited better thermal stability than the deeper area with larger grain size at high temperatures (Figure 3), similar to the reported thermally stable NG Cu [25]. Zhang et al. [52] reported that the grain boundaries of $\mathrm{Cu}$ evolved from low-energy twin boundaries (TBs) possess lower grain boundaries energy than conventional HAGBs. In this study, the grain boundary map in Figure $2 \mathrm{~d}$ reveals that the majority of grain boundaries of nanograins are HAGBs. Our previous work on the microstructure evolution of gradient structured C-22HS Ni-based alloy indicates that these HAGB-dominated NG structures may derive from deformation-induced twin structures [23]. Such transformation led to the formation of grain boundaries in low-energy configuration. Slow grain boundary migration velocity is therefore expected according to Equation (1), indicating the improvement of thermal stability.

The high resolution TEM (HRTEM) image of the nanograins in the topmost NG region in Figure 4a reveals plenty of SFs and nanotwins formed inside the nanograins. The magnified HRTEM image of area $b$ in Figure $4 a$ is shown in Figure $4 b$. Nanotwins with an average twin thickness of $2 \mathrm{~nm}$ were observed. These nanotwins formed inside nanograins are too thin to be detected by ASTAR due to the limited spatial resolution of the technique $(4 \mathrm{~nm})$, which indicates that the proportion of CSL boundaries in the NG region is higher than what was revealed in Figure 2d. These CSL boundaries are also beneficial for improving the thermal stability of GBs [52]. The $\{111\}$ planes forming a twinning relationship and TBs are labeled by solid and dashed lines in Figure $4 b$, respectively. These observations also imply that partial dislocations rather than full dislocation activities dominated the grain refinement process at the nanoscale. The partial dislocations-dominated grain refinement process led to the formation of a thermally stable topmost NG layer because the generation of SFs or nanotwins from grain boundaries plays a critical role in grain boundary relaxation, which impacts the migration of the boundary [26]. Based on the Orowan relation [25], 
the resolved shear stress $\left(\tau_{R S S}\right)$ required for the expansion of a dislocation loop derived from a Frank-Reed source with a diameter of $D$ can be expressed as:

$$
\tau_{R S S}=\mu b / D
$$

where $\mu$ represents the shear modulus and $b$ is the Burgers vector. Hence, the minimum grain size $\left(D^{*}\right)$ required for the multiplication of full dislocations at a given yield strength $\left(\sigma_{y}\right)$ can be calculated by:

$$
D^{*}=\frac{\mu b M}{\sigma_{y}\left(D^{*}\right)}
$$

where $M$ is the Taylor factor ( 3.0 for polycrystalline metals). The shear modulus and Burgers vector for $\mathrm{Ni}$ are $76 \mathrm{GPa}$ and $0.25 \mathrm{~nm}$, respectively. The yield strength $\sigma_{y}\left(D^{*}\right)$ can be calculated by the classic Hall-Petch equation as [53,54]:

$$
\sigma_{y}\left(D^{*}\right)=\sigma_{0}+K\left(D^{*}\right)^{-1 / 2}
$$

where $\sigma_{0}$ is the friction stress and $K$ represents the Hall-Petch slope. Zhou et al. [25] estimated the $D^{*}$ for (full dislocation multiplication mechanism to operate) pure Ni by using Equation (2) and obtained $D^{*}=43 \mathrm{~nm}$, similar to what was calculated by Legros et al. $(38 \mathrm{~nm}$ ) [55]. Considering that the value of $K$ for Ni alloys is higher than that for pure $\mathrm{Ni}$, the calculated $D^{*}$ for IN718 alloys is expected to be smaller than that of pure $\mathrm{Ni}$. Hence, an average $D^{*}$ value $(40 \mathrm{~nm})$ between those reported by Zhao et al. and Legros et al. is adopted in this story. As the grain size of IN718 is smaller than $40 \mathrm{~nm}$, full dislocation activities are superseded by partial dislocation activities, leading to grain boundary relaxation. The experimental observation is consistent with the calculated results. As shown in Figure 3, the average grain size of the relative coarse-grained structures in the thermally stable area is $37 \mathrm{~nm}$ after annealing $\left(700^{\circ} \mathrm{C} / 24 \mathrm{~h}\right)$, whereas prominent grain coarsening occurs in the grain coarsened area with an initial grain size greater than $40 \mathrm{~nm}$.
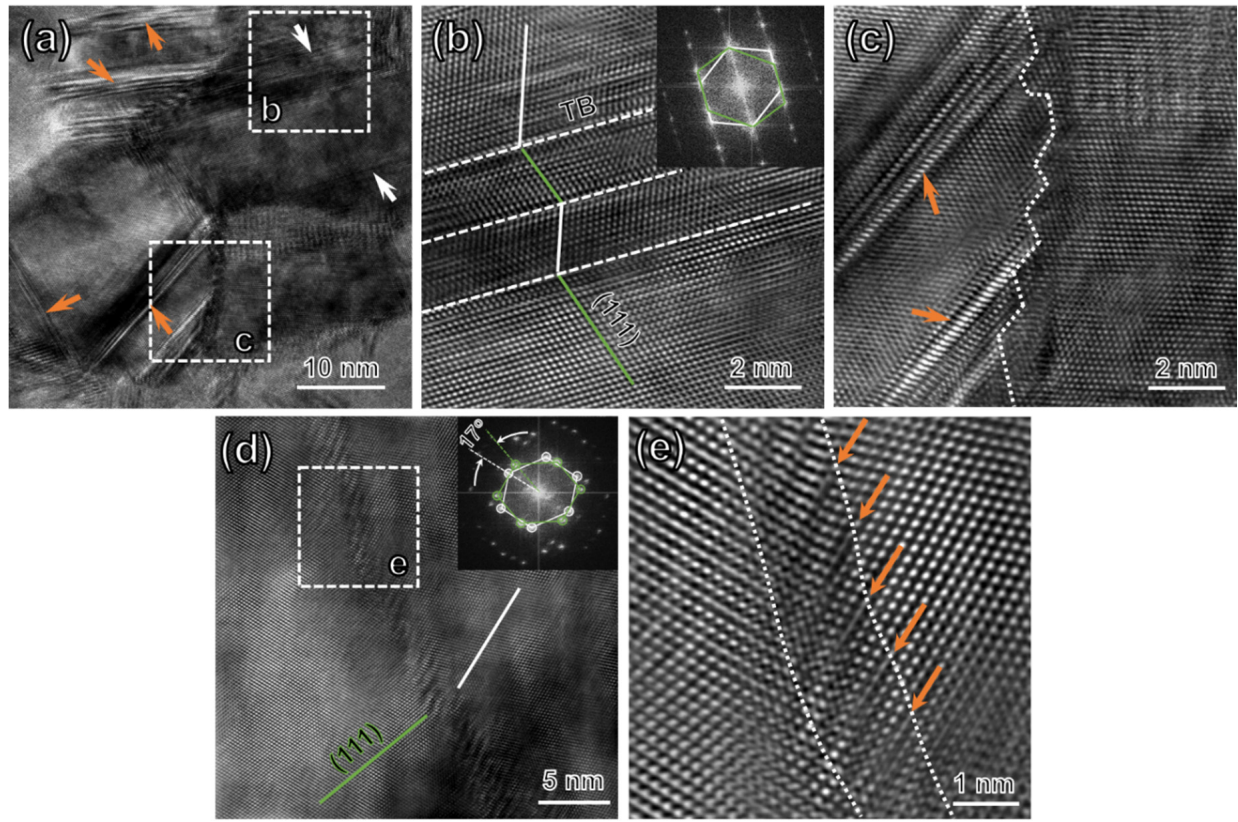

Figure 4. (a) HRTEM image of nanograins containing high-density stacking faults (SFs) and nanotwins (as labeled by orange and white arrows, respectively) formed after SMGT. (b) An atomic-resolution TEM image of the area b in (a) showing the formation of nanotwin structures with an average twin thickness of $2 \mathrm{~nm}$. (c) An atomic-resolution TEM image of the area $\mathrm{c}$ in (a) showing the faceted grain boundary. (d) HRTEM image showing the dissociated HAGBs formed between two adjacent nanograins. (e) An atomic-resolution TEM image of the area e in (d) showing an array of SFs (as labeled by orange arrows) decorated along the dissociated grain boundary. 
We also observed that grain boundaries associated with nanotwins or SFs became faceted frequently, as shown in Figure 4c, where the steps of (111) planes along the grain boundaries are labeled. A previous study reported that the emission of nanoscale twins or SFs from grain boundaries reduces the excess energy of grain boundaries [56], leading to reduced atomic diffusion along the grain boundaries. The emission of SFs and nanotwins in this study led to the formation of faceted grain boundaries. Similar grain boundaries with zig-zag configurations have been reported in nanostructured $\mathrm{Cu}$ with good thermal stability [57]. Generally, a given grain boundary has five crystallographic degrees of freedom (three for the misorientation of the crystallographic axes of one grain and two for the inclination of the boundary between the two adjacent grains) [58]. Grain boundaries naturally find a low-energy configuration that fixes these degrees of freedom, i.e., minimize the free energy of the system pertaining to atomic coordinates or composition by specifying the five degrees of freedom $[58,59]$. For a system where its boundary free energy is anisotropic with respect to the inclination of the grain boundary, the corresponding boundary may lower its free energy by forming faceted planes [58]. Faceting is the process of decomposing the grain boundary into sections with low-energy inclination. Generally, the system with low grain boundary free energy possesses geometric characteristics of low reciprocal volume density of coincidence sites, large interplanar spacing and high planar density of coincidence site, etc. [60]. The twin boundaries in Figure $4 \mathrm{~b}$ and the most densely packed (111) plane of the zig-zagged grain boundaries in Figure 4c are examples of such low-energy grain boundaries. However, the low grain boundary free energy system is not limited to these criteria as there is no direct connection between coincidence and grain boundary energy [60]. The non-CSL 9R structure was found to minimize the grain boundary energy by forming a body-centered-cubic structured grain boundary in the face-centered-cubic matrix $[60,61]$. Faceting has been observed at both micrometer and nanometer scales in several cases $[57,62]$. These faceted grain boundaries have low-energy states and, therefore, are more thermally stable than conventional grain boundaries according to Equation (1).

Grain boundary structure may also transform to a lower-energy state (grain boundary relaxation) through the dissociation of grain boundaries during deformation. The TEM image in Figure 4d shows a dissociated HAGB in the NG IN718 specimen after SMGT. As denoted by dotted lines, broad grain boundaries decorated with plenty of SF-like structures formed. The HRTEM image (of the area e in Figure 4d) in Figure 4e reveals an array of SFs (as noted by orange arrows) emitted from the grain boundary, leading to the broad/dissociated grain boundary with $1 \mathrm{~nm}$ in width. The formation of these SF-decorated broad grain boundaries indicates that grain boundary dissociation may have taken place in the topmost NG region during SMGT, leading to grain boundary relaxation to low-energy states and grain boundary stabilization. Rittner et al. found that grain boundary dissociation generally occurs via the emission of SFs from one boundary and termination at a second boundary [63]. Zhou et al. [25] reported that the formation of both SFs and nanotwins from grain boundaries involves emission of partial dislocations, leading to grain boundary relaxation and stable structures. The dissociation of grain boundaries usually leads to the formation of a wider grain boundary (or three-dimensional boundaries) of up to $1 \mathrm{~nm}$ or more in width, similar to the structures formed in this study.

The grain size evolution of the FNG and CNG structures of the thermally stable area and the grain coarsened area with annealing time is presented in Figure 5a. The calculated minimum grain size $(40 \mathrm{~nm})$ is labeled by the horizontal dotted line. It is evident that the coarsening rate of grains smaller than $40 \mathrm{~nm}$ is lower than that with grain sizes larger than $40 \mathrm{~nm}$. The grain growth kinetic, correlating the grain size $(d)$ to the annealing time $(t)$, can be expressed as [64]:

$$
d^{n}-d_{0}^{n}=k t
$$

where $d_{0}$ is the initial grain size, $n$ represents grain growth exponent and $k$ is a rate constant. The evolution of grain size $(\ln (d))$ and annealing time $(\ln (t))$ in different areas of the specimen is shown in Figure $5 \mathrm{~b}$. The $n$ value can be determined by the slope of linear fit lines. It reveals that the average $n$ value of the thermally stable area with initial grain size 
smaller than $40 \mathrm{~nm}$ is 0.15 , whereas the $n$ value for the grain coarsened area is much greater, 0.59 , confirming a much more sluggish grain growth behavior in the thermally stable NG structure when the initial grain size is smaller than the $D^{*}$.
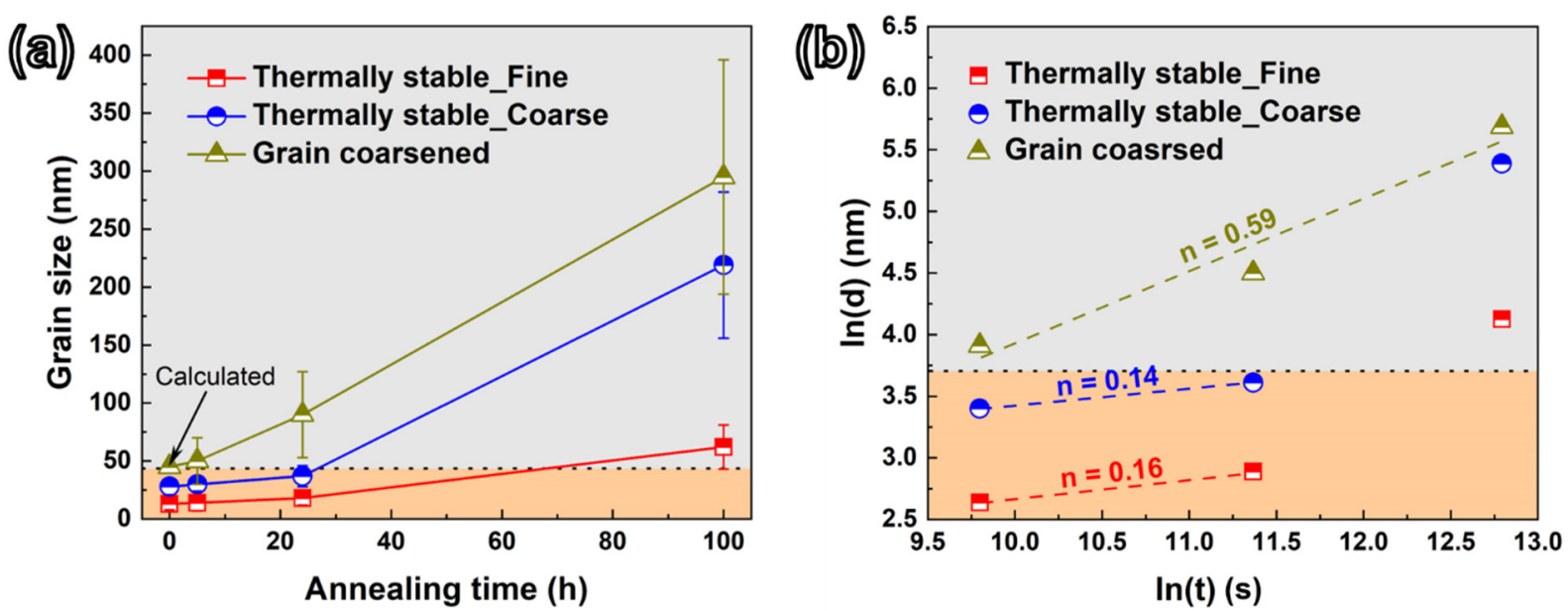

Figure 5. (a) Grain size evolution of FNG and CNG layers in the thermally stable area and the grain coarsened area of IN718 specimens with increasing annealing time. (b) The corresponding plot of $\ln (d) \mathrm{vs}$. $\ln (t)$ at several regions, where $d$ and $t$ are grain size and annealing time, respectively.

\section{Conclusions}

Gradient structures containing an NG surface region have been fabricated in IN718 $\mathrm{Ni}$ alloy using the SMGT technique. The thermal stability studies at $700{ }^{\circ} \mathrm{C}$ up to $100 \mathrm{~h}$ resulted in the following observations.

(1) Nanograins with a grain size smaller than $40 \mathrm{~nm}$ in the deformed surface exhibited significantly enhanced thermal stability compared to grains with larger grain sizes away from the surface.

(2) The average grain growth exponent of thermally stable NG structures with smaller grain sizes $(<40 \mathrm{~nm})$ was 0.15 , in contrast to 0.59 for the larger grains.

(3) TEM studies suggest that the enhanced thermal stability of nanograins was attributed to the generation of grain boundaries in low-energy states during SMGT. The emission of SFs or nanotwins from grain boundaries leads to the dissociation of grain boundaries. The relaxation of grain boundaries to low-energy states results in their subsequent thermal stabilization.

Supplementary Materials: The following are available online at https:/ /www.mdpi.com/2073-435 2/11/1/53/s1, Figure S1: (a) STEM image and the corresponding (b-f) EDS maps of the NG layer of the as-processed IN718 alloy., Figure S2: STEM image and EDS maps of (a) thermally stable area and (b) grain coarsened areas of NG IN718 specimen after annealing at $700^{\circ} \mathrm{C}$ for $24 \mathrm{~h}$.

Author Contributions: J.D. and Z.S. fabricated gradient IN718 alloy. B.Y. and Y.Z. performed heat treatment. J.D. and S.X. prepared TEM samples. J.D., Y.Z., Z.S., T.N., J.L. and H.W. performed TEM imaging and results analyses. J.D. wrote the first draft of the manuscript. X.Z. and H.W. conducted data analyses and manuscript preparation. X.Z. and H.W. designed the project and secured funding. All authors have read and agreed to the published version of the manuscript.

Funding: DOE-Nuclear Energy under DE-NE0008549 and DE-NE0008787.

Institutional Review Board Statement: Not applicable.

Informed Consent Statement: Not applicable.

Data Availability Statement: The raw/processed data required to reproduce these findings cannot be shared at this time due to technical or time limitations. 
Acknowledgments: J. Ding and X. Zhang acknowledge primary financial support by DOE-Nuclear Energy under DE-NE0008549. Z. Shang acknowledges support by DE-NE0008787. S. Xue and H. Wang acknowledge financial support from the U.S. Office of Naval Research (ONR) N00014-20-12043 (for TEM) and N0014-17-1-2087 (for sample preparation). Access to microscopy facilities at Life Science, Birck Nanotechnology Center and School of Materials Engineering at Purdue University, is also acknowledged.

Conflicts of Interest: The authors declare no conflict of interest.

\section{References}

1. Wang, Y.; Wang, K.; Pan, D.; Lu, K.; Hemker, K.; Ma, E. Microsample tensile testing of nanocrystalline copper. Scr. Mater. 2003, 48, 1581-1586. [CrossRef]

2. Youssef, K.M.; Scattergood, R.O.; Murty, K.L.; Horton, J.A.; Koch, C.C. Ultrahigh strength and high ductility of bulk nanocrystalline copper. Appl. Phys. Lett. 2005, 87, 85-88. [CrossRef]

3. Zhao, Y.; Bingert, J.F.; Liao, X.; Cui, B.; Han, K.; Sergueeva, A.V.; Mukherjee, A.K.; Valiev, R.Z.; Langdon, T.G.; Zhu, Y.T. Simultaneously Increasing the Ductility and Strength of Ultra-Fine- Grained Pure Copper. Adv. Mater. 2006, 18, $2949-2953$. [CrossRef]

4. Furukawa, M.; Horita, Z.; Nemoto, M.; Langdon, T.G. Review: Processing of metals by equal-channel angular pressing. J. Mater. Sci. 2001, 36, 2835-2843. [CrossRef]

5. Iwahashi, Y.; Horita, Z.; Nemoto, M.; Langdon, T.G. The process of grain refinement in equal-channel angular pressing. Acta Mater 1998, 46, 3317-3331. [CrossRef]

6. Zhilyaev, A.P.; Langdon, T.G. Using high-pressure torsion for metal processing: Fundamentals and applications. Prog. Mater. Sci. 2008, 53, 893-979. [CrossRef]

7. Zhilyaev, A.P.; Gimazov, A.A.; Soshnikova, E.P.; Révész, Á.; Langdon, T.G. Microstructural characteristics of nickel processed to ultrahigh strains by high-pressure torsion. Mater. Sci. Eng. A 2008, 489, 207-212. [CrossRef]

8. Kawasaki, M.; Langdon, T.G. Review: Achieving superplasticity in metals processed by high-pressure torsion. J. Mater. Sci. 2014, 49, 6487-6496. [CrossRef]

9. Ames, M.; Karos, R.; Michels, A.; Tscho, A.; Birringer, R. Unraveling the nature of room temperature grain growth in nanocrystalline materials. Acta Mater. 2008, 56, 4255-4266. [CrossRef]

10. Thuvander, M.; Abraham, M.; Cerezo, A.; Smith, G.D.W. Thermal stability of electrodeposited nanocrystalline nickel and iron-Nickel alloys Thermal stability of electrodeposited nanocrystalline nickel and iron-Nickel alloys. Mater. Sci. Technol. 2001, 17, 961-970. [CrossRef]

11. Hibbard, G.D.; Radmilovic, V.; Aust, K.T.; Erb, U. Grain boundary migration during abnormal grain growth in nanocrystalline Ni. Mater. Sci. Eng. A 2008, 494, 232-238. [CrossRef]

12. Iordache, M.; Whang, S.; Jiao, Z.; Wang, Z. Grain growth kinetics in nanostructured nickel. Nanostruct. Mater. 1999, 11, 1343-1349. [CrossRef]

13. Popov, V.V.; Popova, E.; Stolbovskiy, A.; Pilyugin, V. Thermal stability of nanocrystalline structure in niobium processed by high pressure torsion at cryogenic temperatures. Mater. Sci. Eng. A 2011, 528, 1491-1496. [CrossRef]

14. Sharma, G.; Varshney, J.; Bidaye, A.C.; Chakravartty, J.K. Grain growth characteristics and its effect on deformation behavior in nanocrystalline Ni. Mater. Sci. Eng. A 2012, 539, 324-329. [CrossRef]

15. Klement, U.; Erb, U.; El-Sherik, A.; Aust, K. Thermal stability of nanocrystalline Ni. Mater. Sci. Eng. A 1995, 203, 177-186. [CrossRef]

16. Jiang, H.; Zhu, Y.T.; Butt, D.P.; Alexandrov, I.V.; Lowe, T.C. Microstructural evolution, microhardness and thermal stability of HPT-processed Cu. Mater. Sci. Eng. A 2000, 290, 128-138. [CrossRef]

17. Fang, T.H.; Li, W.L.; Tao, N.R.; Lu, K. Revealing Extraordinary Intrinsic Tensile Plasticity in Gradient Nano-Grained Copper. Science 2011, 331, 1587-1590. [CrossRef]

18. Huang, H.W.; Wang, Z.B.; Lu, J.; Lu, K. Fatigue behaviors of AISI 316L stainless steel with a gradient nanostructured surface layer. Acta Mater. 2015, 87, 150-160. [CrossRef]

19. Wu, X.; Jiang, P.; Chen, L.; Yuan, F.; Zhu, Y. Extraordinary strain hardening by gradient structure. Proc. Natl. Acad. Sci. USA 2014, 111, 7197-7201. [CrossRef]

20. Wu, X.; Jiang, P.; Chen, L.; Zhang, J.F.; Yuan, F.P.; Zhu, Y.T. Synergetic Strengthening by Gradient Structure. Mater. Res. Lett. 2014, 2, 185-191. [CrossRef]

21. Ding, J.; Shang, Z.; Zhang, Y.F.; Su, R.; Li, J.; Wang, H.; Zhang, X. Tailoring the thermal stability of nanocrystalline Ni alloy by thick grain boundaries. Scr. Mater. 2020, 182, 21-26. [CrossRef]

22. Liu, X.; Zhang, H.; Lu, K. Formation of nano-laminated structure in nickel by means of surface mechanical grinding treatment. Acta Mater. 2015, 96, 24-36. [CrossRef]

23. Ding, J.; Li, Q.; Li, J.; Xue, S.; Fan, Z.; Wang, H.; Zhang, X. Mechanical behavior of structurally gradient nickel alloy. Acta Mater. 2018, 149, 57-67. [CrossRef]

24. Ding, J.; Neffati, D.; Li, Q.; Su, R.; Li, J.; Xue, S.; Shang, Z.; Zhang, Y.F.; Wang, H.; Kulkarni, Y.; et al. Thick grain boundary induced strengthening in nanocrystalline Ni alloy. Nanoscale 2019, 11, 23449-23458. [CrossRef] [PubMed] 
25. Zhou, X.; Li, X.; Lu, K. Enhanced thermal stability of nanograined metals below a critical grain size. Science 2018, 360, 526-530. [CrossRef] [PubMed]

26. Zhou, X.; Li, X.; Lu, K. Size Dependence of Grain Boundary Migration in Metals under Mechanical Loading. Phys. Rev. Lett. 2019, 122, 126101. [CrossRef]

27. Zhang, H.J.; Li, C.; Liu, Y.C.; Guo, Q.Y.; Huang, Y.; Li, H.J.; Yu, J.X. Effect of hot deformation on $\gamma^{\prime \prime}$ and $\delta$ phase precipitation of Inconel 718 alloy during deformation\&isothermal treatment. J. Alloys Compd. 2017, 716, 65-72.

28. Dreler, A.; Oberwinkler, B.; Primig, S.; Turk, C.; Povoden-Karadeniz, E.; Heinemann, A.; Ecker, W.; Stockinger, M. Experimental and numerical investigations of the $\gamma^{\prime \prime}$ and $\gamma^{\prime}$ precipitation kinetics in Alloy 718. Mater. Sci. Eng. A 2018, 723, 314-323. [CrossRef]

29. Lawitzki, R.; Hassan, S.; Karge, L.; Wagner, J.; Wang, D.; von Kobylinski, J.; Krempaszky, C.; Hofmann, M.; Gilles, R.; Schmitz, G. Differentiation of $\gamma^{\prime}$ - and $\gamma^{\prime \prime}$ - precipitates in Inconel 718 by a complementary study with small-angle neutron scattering and analytical microscopy. Acta Mater. 2019, 163, 28-39. [CrossRef]

30. Anderson, M.; Thielin, A.L.; Bridier, F.; Bocher, P.; Savoie, J. $\delta$ Phase precipitation in Inconel 718 and mechanical properties. Mater. Sci. Eng. A 2017, 679, 48-55. [CrossRef]

31. Mei, Y.; Liu, C.; Liu, Y.; Zhou, X.; Yu, L.; Li, C.; Ma, Z.; Huang, Y. Effects of cold rolling on the precipitation and the morphology of $\delta$-phase in Inconel 718 alloy. J. Mater. Res. 2016, 31, 443-454. [CrossRef]

32. Azadian, S.; Wei, L.-Y.; Warren, R. Delta phase precipitation in Inconel 718. Mater. Charact. 2004, 53, 7-16. [CrossRef]

33. Wang, Z.; Guan, K.; Gao, M.; Li, X.; Chen, X.; Zeng, X. The microstructure and mechanical properties of deposited-IN718 by selective laser melting. J. Alloys Compd. 2012, 513, 518-523. [CrossRef]

34. Wang, Y.; Shao, W.; Zhen, L.; Zhang, B. Hot deformation behavior of delta-processed superalloy 718. Mater. Sci. Eng. A 2011, 528, 3218-3227. [CrossRef]

35. Amato, K.; Gaytan, S.; Murr, L.; Martinez, E.C.; Shindo, P.; Hernandez, J.; Collins, S.F.; Medina, F.S. Microstructures and mechanical behavior of Inconel 718 fabricated by selective laser melting. Acta Mater. 2012, 60, 2229-2239. [CrossRef]

36. Chamanfar, A.; Sarrat, L.; Jahazi, M.; Asadi, M.; Weck, A.; Koul, A. Microstructural characteristics of forged and heat treated Inconel-718 disks. Mater. Des. 2013, 52, 791-800. [CrossRef]

37. Liu, W.; Chen, Z.; Xiao, F.; Yao, M.; Wang, S.; Liu, R. Effect of cold rolling on the kinetics of $\delta$ phase precipitation in inconel 718. Metall. Mater. Trans. A 1999, 30A, 31-40. [CrossRef]

38. Slama, C.; Servant, C.; Cizeron, G. Aging of the Inconel 718 alloy between 500 and $750{ }^{\circ}$ C. J. Mater. Res. 1997, 12, $2298-2316$. [CrossRef]

39. Thomas, A.; El-Wahabi, M.; Cabrera, J.; Prado, J. High temperature deformation of Inconel 718. J. Mater. Process. Technol. 2006, 177, 469-472. [CrossRef]

40. Fisk, M.R.; Andersson, J.; Du Rietz, R.; Haas, S.; Hall, S.A. Precipitate evolution in the early stages of ageing in Inconel 718 investigated using small-angle x-ray scattering. Mater. Sci. Eng. A 2014, 612, 202-207. [CrossRef]

41. Mei, Y.; Liu, Y.; Liu, C.; Li, C.; Yu, L.; Guo, Q.; Li, H. Effects of cold rolling on the precipitation kinetics and the morphology evolution of intermediate phases in Inconel 718 alloy. J. Alloys Compd. 2015, 649, 949-960. [CrossRef]

42. Kuo, Y.-L.; Horikawa, S.; Kakehi, K. The effect of interdendritic $\delta$ phase on the mechanical properties of Alloy 718 built up by additive manufacturing. Mater. Des. 2017, 116, 411-418. [CrossRef]

43. Zhang, H.; Li, C.; Guo, Q.; Ma, Z.; Huang, Y.; Li, H.; Liu, Y. Delta precipitation in wrought Inconel 718 alloy; the role of dynamic recrystallization. Mater. Charact. 2017, 133, 138-145. [CrossRef]

44. Nalawade, S.A.; Sundararaman, M.; Singh, J.B.; Verma, A.; Kishore, R. Precipitation of $\gamma^{\prime}$ phase in $\delta$-precipitated Alloy 718 during deformation at elevated temperatures. Mater. Sci. Eng. A 2010, 527, 2906-2909. [CrossRef]

45. Huang, Y.; Langdon, T.G. The evolution of delta-phase in a superplastic Inconel 718 alloy. J. Mater. Sci. 2007, 42, 421-427. [CrossRef]

46. Rong, Y.H.; Chen, S.P.; Hu, G.X.; Gao, M.; Wei, R.P. Prediction and characterization of variant electron diffraction patterns for $\gamma^{\prime \prime}$ and $\delta$ precipitates in an INCONEL 718 alloy. Metall. Mater. Trans. A 1999, 30A, 2297-2303. [CrossRef]

47. Burke, J.; Turnbull, D. Recrystallization and grain growth. Prog. Met. Phys. 1952, 3, 220-292. [CrossRef]

48. Schuler, J.D.; Donaldson, O.K.; Rupert, T.J. Amorphous complexions enable a new region of high temperature stability in nanocrystalline Ni-W. Scr. Mater. 2018, 154, 49-53. [CrossRef]

49. Muthaiah, V.S.; Babu, L.H.; Koch, C.C.; Mula, S. Feasibility of formation of nanocrystalline Fe-Cr-Y alloys: Mechanical properties and thermal stability. Mater. Charact. 2016, 114, 43-53. [CrossRef]

50. Li, L.; Saber, M.; Xu, W.; Zhu, Y.; Koch, C.C.; Scattergood, R.O. High-temperature grain size stabilization of nanocrystalline Fe-Cr alloys with Hf additions. Mater. Sci. Eng. A 2014, 613, 289-295. [CrossRef]

51. A Darling, K.; Kecskes, L.J.; Atwater, M.; Semones, J.; Scattergood, R.; Koch, C. Thermal stability of nanocrystalline nickel with yttrium additions. J. Mater. Res. 2013, 28, 1813-1819. [CrossRef]

52. Zhang, Y.; Tao, N.; Lu, K. Mechanical properties and rolling behaviors of nano-grained copper with embedded nano-twin bundles. Acta Mater. 2008, 56, 2429-2440. [CrossRef]

53. Hall, E.O. The Deformation and Ageing of Mild Steel. Proc. Phys. Soc. London Sect. B 1951, 64, 747-753. [CrossRef]

54. Petch, J.N. The Cleavage Strength of Polycrystals. J. Iron Steel Inst. 1953, 174, 25-28.

55. Legros, M.; Elliott, B.R.; Rittner, M.N.; Weertman, J.R.; Hemker, K.J. Microsample tensile testing of nanocrystalline metals. Philos. Mag. A 2000, 80, 1017-1026. [CrossRef] 
56. Chen, K.-C.; Wu, W.-W.; Liao, C.-N.; Chen, L.-J.; Tu, K.N. Observation of Atomic Diffusion at Twin-Modified Grain Boundaries in Copper. Science. 2008, 321, 1066-1069. [CrossRef]

57. Li, X.; Zhou, X.; Lu, K. Rapid heating induced ultrahigh stability of nanograined copper. Sci. Adv. 2020, 6, eaaz8003. [CrossRef]

58. Wu, Z.; Zhang, Y.-W.; Srolovitz, D. Grain boundary finite length faceting. Acta Mater. 2009, 57, 4278-4287. [CrossRef]

59. Priedeman, J.L.; Olmsted, D.L.; Homer, E.R. The role of crystallography and the mechanisms associated with migration of incoherent twin grain boundaries. Acta Mater. 2017, 131, 553-563. [CrossRef]

60. Straumal, B.B.; Kogtenkova, O.A.; Gornakova, A.S.; Sursaeva, V.G.; Baretzky, B. Review: Grain boundary faceting-roughening phenomena. J. Mater. Sci. 2016, 51, 382-404. [CrossRef]

61. Wolf, U.; Ernst, F.; Muschik, T.; Finnis, M.W.; Fischmeister, H.F. The influence of grain boundary inclination on the structure and energy of $\sigma=3$ grain boundaries in copper. Philos. Mag. A. 1992, 66, 991-1016. [CrossRef]

62. Bishop, G.H.; Hartt, W.; Bruggeman, G.A. Grain boundary faceting of <1010> tilt boundaries in zinc-II. Acta Metall. 1971, 19, 37-47. [CrossRef]

63. Rittner, J.; Seidman, D.; Merkle, K. Grain-boundary dissociation by the emission of stacking faults. Phys. Rev. B Condens. Matter Mater. Phys. 1996, 53, 4241-4244. [CrossRef] [PubMed]

64. Sun, C.; Yang, Y.; Liu, Y.; Hartwig, K.T.; Wang, H.; Maloy, S.A.; Allen, T.R.; Zhang, X. Thermal stability of ultrafine grained Fe-Cr-Ni alloy. Mater. Sci. Eng. A. 2012, 542, 64-70. [CrossRef] 